\section{Quantitative Evaluation of Solute Hydrogen Effect on Dislocation Density in a Low-carbon Stable Austenitic Stainless Steel}

\author{
Kengo KAMEI, ${ }^{1)}$ Yuuki KOUMURA, ${ }^{1)}$ \\ Arnaud MACADRE ${ }^{2 * *}$ and Koichi GODA ${ }^{2)}$
}

1) Yamaguchi University, Graduate School of Sciences and Technology for Innovation, 2-16-1 Tokiwadai, Ube, Yamaguchi, 7558611 Japan.

2) Yamaguchi University, Department of Mechanical Engineering, 2-16-1 Tokiwadai, Ube, Yamaguchi, 755-8611 Japan.

(Received on November 12, 2020; accepted on December 15, 2020; J-STAGE Advance published date: January 21, 2021)

The effects of hydrogen on dislocations are generally understood through Transmission Electron Microscope studies. Novel methods of X-Ray Diffraction analysis provide the means of quantitative measurements of dislocation densities and the evolution of crossslip in austenitic stainless steels. In a low-carbon austenitic stainless steel (SUS316L) with and without solute hydrogen, and strained by cold-rolling, the maximum dislocation densities were measured, with hydrogen clearly increasing the maximum dislocation density, and the ratio of screw dislocations was shown to be similar regardless of hydrogen content.

KEY WORDS: austenitic steel; hydrogen; X-ray diffraction; dislocation.

\section{Introduction}

Investigations on the effects of hydrogen on steel properties continue. While data is accumulating for low-alloy steels, ${ }^{1)}$ austenitic stainless, ${ }^{2-5)}$ pure materials ${ }^{6)}$ etc., recent articles $^{7-9)}$ show that a consensus on hydrogen embrittlement has not been reached yet. With theories on the effects of solute hydrogen in metals at the nanoscale (effect of hydrogen on dislocation activity, ${ }^{8,10,11)}$ or on point-defect formation $^{7,12)}$ ), the link between nanoscale effects and macroscale results is not always obvious (such as apparent strengthening with hydrogen in austenitic steels with concurrent embrittlement ${ }^{4,13,14)}$ ). Those theories have greatly advanced the understanding of hydrogen-induced degradation, and direct observations of the enhancement of dislocation activity ${ }^{8,11)}$ have allowed to qualify the effect of hydrogen, however, quantitative analyses are lacking.

This article focuses on a quantitative analysis of the dislocation density in steel with solute hydrogen. Indeed, the HELP mechanism explains how dislocation activity is enhanced and localized by solute hydrogen. However, it remains difficult to establish how much and at what rate dislocation activity is increased. Using cold rolling to obtain

\footnotetext{
* Corresponding author: E-mail: macadre@yamaguchi-u.ac.jp
}

strain-controlled deformation, along with newer methods of data treatment for X-ray diffraction (XRD), we measured the evolution of dislocation densities in stable austenite with solute hydrogen.

\section{Experimental Procedure}

The steel is SUS316L (chemical composition in Table 1). It was received as $3-\mathrm{mm}$-thick plates. The heat treatment was as follows: a reference material was annealed at $1273 \mathrm{~K}$ for 4 hours and furnace cooled (cooling rate of $\sim 2$ K. min $^{-1}$ ) to ensure a minimal defect density in the material. Other plates were annealed at $1273 \mathrm{~K}$ for 2 hours and air-cooled. The plates were then polished to a buff $(1-\mu \mathrm{m}$ alumina). The final plate size was $3 \times 15 \times 50 \mathrm{~mm}$.

After all the plate samples were polished, hydrogen exposure was conducted in $11 \mathrm{MPa} \mathrm{H}_{2}$ gas at $543 \mathrm{~K}$ for 309 hours. The hydrogen-charged samples (H-charged) were subsequently held in liquid nitrogen.

All the plates (3-mm thick, both uncharged and H-charged) were cold-rolled at room temperature (R.T., $300 \mathrm{~K}$ ), with a reduction ratio of $0.1 \mathrm{~mm} /$ pass (the roll circumferential speed was measured to be $0.046 \mathrm{~m} . \mathrm{s}^{-1}$ ), to various reduction ratios; the maximum reduction ratio in thickness being $70 \%$, since above this value, strain-induced martensite started forming.

Specimens for XRD were cut out $\left.\left(10 \times 10 \times 0.8-3 \mathrm{~mm}^{3}\right)\right)$ and polished to a buff, before being electrochemically polished in a phosphoric acid solution with a stainless steel cathode, with a constant current of $\sim 6 \mathrm{~V}$ at a current density of $\sim 1.2 \mathrm{~A} . \mathrm{cm}^{-2}$ ). The electropolishing was stopped when $50 \mu \mathrm{m}$ were removed from the XRD analysis surface, to remove any residual strains caused by previous polishing. ${ }^{14)}$

The XRD measurements were conducted with $\mathrm{Cu}-\mathrm{K} \alpha 2$ $(40 \mathrm{kV}), 30 \mathrm{~mA})$ ), the measurement range was $40-145^{\circ}$, with a step size of $0.02^{\circ}$, and rotating speed of $0.007^{\circ} . \mathrm{s}^{-1}$,

The analysis of the dislocation density was done by the method explained in the articles by Takaki et al.: ${ }^{15-21)}$ it uses the modified Williamson-Hall plot $\left.{ }^{22}\right)(\mathrm{m}-\mathrm{WH})$ combined with their Direct Fitting (DF) method, designed to remove elastic anisotropy. The modified Williamson-Hall plot is defined as (with the DF method):

$$
\Delta K^{\prime}=\frac{0.9}{D}+A \sqrt{\frac{\pi}{2}} b \sqrt{\rho}\left(K^{\prime} \sqrt{C}\right)+O\left(K^{\prime} \sqrt{C}\right)^{2}
$$

with $\Delta K=\left(\beta_{h k l} \cos \theta_{h k l}\right) / \lambda, K=\left(2 \sin \theta_{h k l}\right) / \lambda$, and $K^{\prime}=$ $K / \omega_{h k l}$ with $\omega_{h k l}=E_{h k l} / E_{110} . \beta_{h k l}[\mathrm{rad}]$ is the full width at half-maximum $(F W H M)$ for the $(h k l)$ orientation, $\theta_{h k l}[\mathrm{rad}]$ the peak angle, $\lambda$ the wavelength (for copper: $\lambda=1.5406$ $\AA), D[\mu \mathrm{m}]$ the crystallite size (different from the grain size) and $\varepsilon[-]$ is the lattice strain. $b$ is the Burgers vector $(b=0.257 \mathrm{~nm})$ and $A$ is a parameter dependent on the dislocation stress field $(A=0.6), \rho\left[\mathrm{m} . \mathrm{m}^{-3}\right]$ the dislocation density. $C$ is the contrast factor, obtained as follows: $C=$ $C_{h 00}\left(1-q H^{2}\right), C_{h 00}=0.307+S(0.312-0.307)$, and $q=$ $1.710+S(2.420-1.710)$. The value $S$ is the ratio of screw "character" in dislocations ( $S$ close to 1 or 0 would mean a very flat dislocation loop, with large screw or edge segments, respectively), $H$ is the orientation factor for $(h k l)$ $\left(H^{2}=\left(h^{2} k^{2}+k^{2} l^{2}+l^{2} h^{2}\right) /\left(h^{2}+k^{2}+l^{2}\right)\right)$.

\section{Results}

The hydrogen content was estimated at $C_{H}=28$ mass ppm, calculated using the data of Murakami et al. ${ }^{23)}$ show that 70 hours are enough for the 3-mm-thick plates to be saturated with solute hydrogen under $11 \mathrm{MPa}$ at $543 \mathrm{~K}$.

Inverse Pole Figure maps (IPF maps) of the microstructure for the specimen prepared for cold-rolling, with and 
without $\mathrm{H}_{2}$ gas exposure, are shown in Fig. 1. The grain size is about $76 \mu \mathrm{m}$ and the texture shows an apparent majority of grains in the (101) orientation. $\mathrm{H}_{2}$ exposure did not appear to affect the texture nor the grain size.

Figure 2 shows the diffraction peaks of $0 \%$ cold-rolled samples and $20 \%$ cold-rolled samples. In the non-deformed material, the (111) peak was very faint in both the $\mathrm{H}$-charged and uncharged conditions, probably owing to the texture mentioned previously. In the $20 \%$ cold-rolled material, all peaks were clearly identifiable, due to the plastic deformation. The peaks were of similar shape and height, with slightly higher peaks for the uncharged $20 \%$ coldrolled material. It should be noted that for low strains $(\varepsilon<$ $0.05)$, the peaks were extremely narrow in both uncharged and $\mathrm{H}$-charged material, leading to increased error.

Figure 3(a) shows the dislocation density for all samples against the true strain $\varepsilon$, calculated from the rolling reduction ratio $r[-])(\varepsilon=-2 / \sqrt{3} \times \ln (1-r))$. At all strains, the $\mathrm{H}$-charged material exhibits a higher dislocation density. Even for unstrained material $(\varepsilon=0.0)$, the dislocation density was higher for the H-charged material. The lattice parameter varied slightly but uniformly with H-charging, and cannot account on its own for the difference. For both materials, the dislocation density appears to increase linearly with strain at first, with a larger slope for the H-charged plates. For strains above $\varepsilon=0.4$, the slope decreases and it appears that the dislocation density, for both uncharged and H-charged material, reaches a maximum: uncharged $\rho_{\mathrm{U}} \leq$

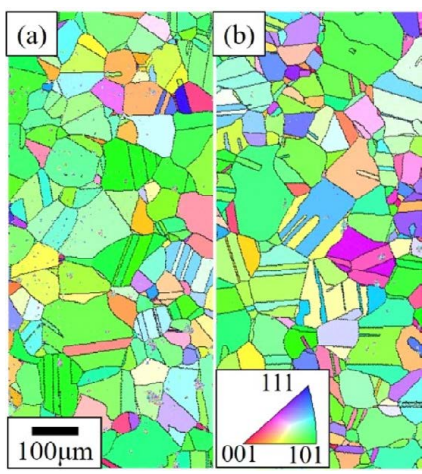

Fig. 1. Inverse Pole Figure maps of unstrained SUS316L (a) uncharged, and (b) hydrogen-charged. (Online version in color.)

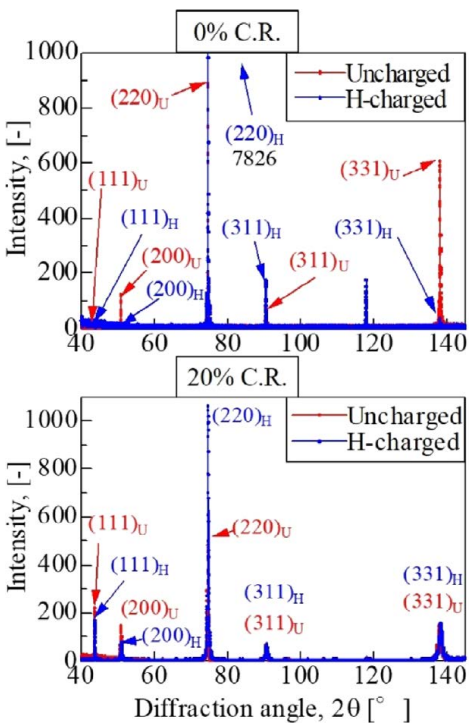

Fig. 2. Diffraction peaks of $0 \%$ cold-rolled samples (above) and $20 \%$ cold-rolled samples (below) for hydrogen-charged and uncharged SUS316L (values in black indicate the peak intensity). (Online version in color.)
$2.5 \times 10^{15} \mathrm{~m} . \mathrm{m}^{-3} ;$ H-charged $\rho_{\mathrm{H}} \leq 3.2 \times 10^{15} \mathrm{~m} . \mathrm{m}^{-3}$.

In this analysis, a parameter $S$ is used, which represents the ratio of "screw character", i.e. how much length of dislocation has a screw-dislocation character compared to edgedislocation character ( $S$ close to 1 or 0 would mean a very flat dislocation loop, with large screw or edge segments, respectively). This $S$ parameter is plotted against the true strain $\varepsilon$ in Fig. 3(b). Due to the difficulty of measuring the full width at half-maximum for low strains, there are variations at low strains. As the strain increases, the $S$ parameter decreases, indicating that the edge character of dislocations becomes longer than the screw character. This trend is the same and takes similar values for both $\mathrm{H}$-charged and uncharged material.

Electron Channeling Contrast Imaging (ECCI) taken at $20 \%$ C.R. shows that dislocation cells did not appear to vary greatly in size between H-charged and uncharged material: large cells with an average diameter of $0.2 \mu \mathrm{m}$ were seen along with smaller cells in-between (Fig. 4).

\section{Discussion}

According to the review of Martin et al., ${ }^{9)}$ the effects of hydrogen on dislocation are the following: increase of velocity (two to ten times), shorter spacing between dislocations (especially in pile-ups), and a reduced tendency to cross-slip (reduced stacking fault energy, stabilization of edge component, and increased energy to form the neces-

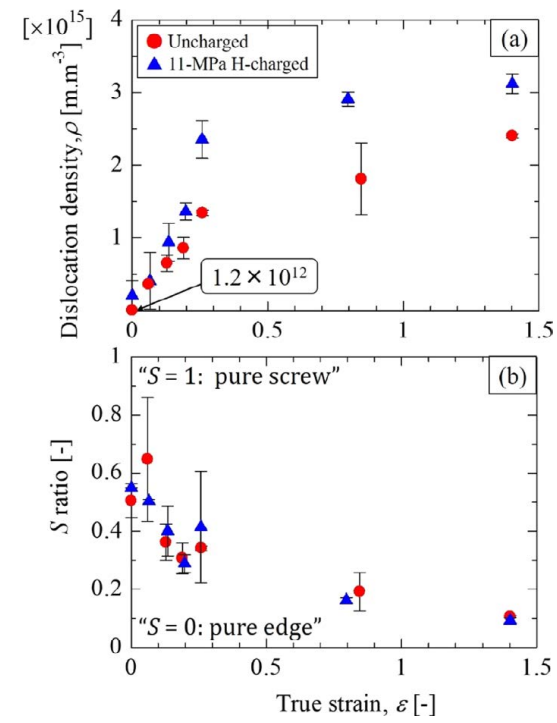

Fig. 3. Evolution of dislocations against the true strain $\varepsilon$ : (a) dislocation density, (b) $S$ ratio of screw dislocations. (Online version in color.)

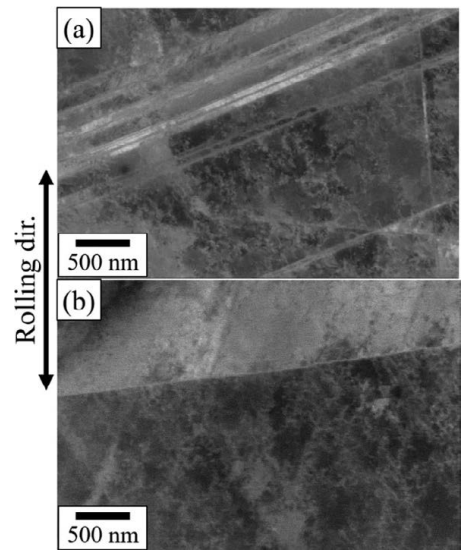

Fig. 4. ECC images after $20 \%$ C.R. for (a) uncharged, and (b) hydrogen-charged SUS316L. 
sary constriction prior to cross-slip). The latter has also been confirmed by various studies on Nickel. ${ }^{6,24,25)}$ The reason for the increase of dislocation velocity itself is still a matter of debate and can be attributed to a reduction in interaction energy between dislocations and obstacles (mostly for edge components), ${ }^{8)}$ or a decrease of dislocation formation energy (for all dislocations). ${ }^{26,27)}$ Additionally, Delafosse ${ }^{25)}$ mentioned that in a pure nickel single crystal, the dislocation structure for the uncharged crystal was a well-developed cell structure (stage III deformation), while the H-charged crystal only displayed a planar dislocation structure (stage II deformation). Similarly an increased density of defects (vacancies) due to hydrogen was reported by Yagodzinskyy et al. in single crystal SUS316L. ${ }^{28)}$ Based on these reports, it is reasonable to predict an increase in the dislocation density of H-charged SUS316L, a decrease of cross-slip, along with the development of a dislocation structure slightly different from uncharged SUS316L.

Here, the maximum dislocation densities were approximately $\rho_{\mathrm{H}}=3.2 \times 10^{15} \mathrm{~m} \cdot \mathrm{m}^{-3}$ (H-charged) and $\rho_{\mathrm{U}}=$ $2.5 \times 10^{15} \mathrm{~m} . \mathrm{m}^{-3}$ (uncharged). The dislocation density in SUS316L at high strains $\left(\varepsilon_{\max } \approx 1.50\right)$ with solute hydrogen has not been reported yet. Masumura et al. ${ }^{29)}$ reported a maximum dislocation density of about $3.0 \times 10^{15} \mathrm{~m} . \mathrm{m}^{-3}$ for $\varepsilon \approx 0.31$ using the $\mathrm{mWH}$ and William-Averbach methods in low- and high-nitrogen SUS316L (in Fig. 3(a), for $\varepsilon \approx 0.30$, $\rho_{\mathrm{U}} \approx 1.6 \times 10^{15} \mathrm{~m} . \mathrm{m}^{-3}$ ).

The ratio of screw dislocations, $S$, evolved very similarly (decrease with increasing strain), and with the same values, with and without hydrogen. This means that, for a dislocation loop at a given strain with pure edge, mixed, and pure screw characters in a finite volume, the addition of solute hydrogen would have increased the loop size (total length) but not its shape. As seen in the ECCI images (Fig. 4), dislocation cells are present in both uncharged and $\mathrm{H}$-charged samples at $20 \%$ C.R. Thus, at $\varepsilon \approx 0.25$ a significant amount of cross-slip had occurred, regardless of the hydrogen content in the samples, confirming the decrease of the $S$ ratio with increasing strain (Fig. 3(b)) as cross-slip and recovery occurred in both conditions.

Cross-slip should be reduced to some extent by hydrogen according to the HELP theory, but here the data and observations do not fully support this view. A few explanations are possible: (1) the hydrogen content is enough for increased dislocation activity, but the cross-slip probability is not reduced significantly, either owing to an insufficient hydrogen content, or to too fast a strain rate; (2) according to the defactant theory, ${ }^{30}$ hydrogen will enhance the formation and velocity of all dislocations (edge and screw) but without clearly reducing cross-slip; (3) the strain-controlled processing by cold-rolling, and the high strain levels reached here do not allow for cross-slip restriction.

Finally, the dislocation density is calculated on the basis of an " $A$ value" ( $A=0.6$ for austenitic steels), which is dependent on the stress field of a dislocation. According to Ferreira and Robertson, ${ }^{31)}$ the variation of the stress field of a dislocation due to hydrogen can be estimated to effect a reduction of the dislocation spacing of $10 \%$. However, using this estimation in our calculations did not show a different effect of hydrogen on the dislocation density: the dislocation density simply further increases with decreasing dislocation spacing. Further study is necessary to fully appreciate the hydrogen effects on the parameters used for XRD analysis.

\section{Conclusions}

(1) Cold-rolling of hydrogen-charged and uncharged plates followed by XRD analysis allowed the quantitative evaluation of the dislocation density in SUS316L. This can be a useful tool for diagnosis or prognosis of the evolution of deformation in hydrogen environment.

(2) The dislocation density increases relatively linearly with increasing strain to $\varepsilon \approx 0.40$, regardless of the presence or absence of hydrogen, with maximum densities estimated at $\rho_{\mathrm{H}}=3.2 \times 10^{15} \mathrm{~m} \cdot \mathrm{m}^{-3}$ (H-charged) and $\rho_{\mathrm{U}}=2.5 \times 10^{15}$ $\mathrm{m} . \mathrm{m}^{-3}$ (uncharged), at a maximum true strain of $\varepsilon \approx 1.40$.

(3) The ratio of screw dislocation character evolved in similar ways for both uncharged and H-charged SUS316L, i.e. hydrogen did not appear to affect significantly the length of dislocation with screw character. Dislocation cells were observed, confirming that cross-slip occurred with and without hydrogen.

\section{REFERENCES}

1) H. Fuchigami, H. Minami and M. Nagumo: Philos. Mag. Lett., 86 (2006), 21. https://doi.org/10.1080/09500830500482316

2) T. Michler and J. Naumann: Int. J. Hydrog. Energy, 35 (2010), 1485. https://doi.org/10.1016/j.ijhydene.2009.10.050

3) T. Michler, C. San Marchi, J. Naumann, S. Weber and M. Martin: Int. J. Hydrog. Energy, 37 (2012), 16231. https://doi.org/10.1016/j. ijhydene.2012.08.071

4) C. San Marchi, B. P. Somerday, X. Tang and G. H. Schiroky: Int. J. Hydrog. Energy, 33 (2008), 889. https://doi.org/10.1016/j. ijhydene.2007.10.046

5) C. San Marchi, T. Michler, K. A. Nibur and B. P. Somerday: Int. J. Hydrog. Energy, 35 (2010), 9736. https://doi.org/10.1016/j. ijhydene.2010.06.018

6) S. K. Lawrence, Y. Yagodzinskyy, H. Hänninen, E. Korhonen, F. Tuomisto, Z. D. Harris and B. P. Somerday: Acta Mater., 128 (2017), 218. https://doi.org/10.1016/j.actamat.2017.02.016

7) I. M. Robertson: Eng. Fract. Mech., 68 (2001), 671. https://doi. org/10.1016/S0013-7944(01)00011-X

8) I. M. Robertson, P. Sofronis, A. Nagao, M. L. Martin, S. Wang, D. W. Gross and K. E. Nygren: Metall. Mater. Trans. B, 46 (2015), 1085. https://doi.org/10.1007/s11663-015-0325-y

9) M. L. Martin, M. Dadfarnia, A. Nagao, S. Wang and P. Sofronis: Acta Mater., 165 (2019), 734. https://doi.org/10.1016/j.actamat.2018.12.014

10) M. Nagumo and K. Takai: Acta Mater., 165 (2019), 722. https://doi. org/10.1016/j.actamat.2018.12.013

11) M. Nagumo: ISIJ Int., 52 (2012), 168. https://doi.org/10.2355/ isijinternational.52.168

12) Y. Mine, N. Horita, Z. Horita and K. Takashima: Int. J. Hydrog. Energy, 42 (2017), 15415. https://doi.org/10.1016/j.ijhydene.2017.04.249

13) A. Macadre, T. Tsuchiyama and S. Takaki: Materialia, 8 (2019), 100514. https://doi.org/10.1016/j.mtla.2019.100514

14) F. Jiang, K. Hirata, T. Masumura, T. Tsuchiyama and S. Takaki: ISIJ Int., 58 (2018), 376. https://doi.org/10.2355/isijinternational. ISIJINT-2017-578

15) S. Takaki, F. Jiang, T. Masumura and T. Tsuchiyama: ISIJ Int., 58 (2018), 769. https://doi.org/10.2355/isijinternational.ISIJINT-2017-642

16) S. Takaki, T. Masumura and T. Tsuchiyama: ISIJ Int., 58 (2018), 2354. https://doi.org/10.2355/isijinternational.ISIJINT-2018-517

17) S. Takaki, T. Masumura, F. Jiang and T. Tsuchiyama: J. Soc. Mater. Sci., Jpn., 67 (2018), 855 (in Japanese). https://doi.org/10.2472/jsms.67.860

18) T. Masumura, S. Takaki, F. Jiang and T. Tsuchiyama: Tetsu-toHagané, 104 (2018), 717 (in Japanese). https://doi.org/10.2355/ tetsutohagane.TETSU-2018-095

19) H. Toraya: J. Crystallogr. Soc. Jpn., 34 (1992), 86 (in Japanese). https://doi.org/10.5940/jcrsj.34.86

20) F. Jiang, T. Masumura, K. Hirata, T. Tsuchiyama and S. Takaki: Int. J. Plast., 112 (2019), 89. https://doi.org/10.1016/j.ijplas.2018.08.006

21) S. Takaki, T. Masumura and T. Tsuchiyama: ISIJ Int., 59 (2019), 567. https://doi.org/10.2355/isijinternational.ISIJINT-2018-623

22) T. Ungár and A. Borbély: Appl. Phys. Lett., 69 (1996), 3173. https:// doi.org/10.1063/1.117951

23) Y. Murakami, T. Kanezaki and Y. Mine: Metall. Mater. Trans. A, 41 (2010), 2548. https://doi.org/10.1007/s11661-010-0275-6

24) M. Wen, S. Fukuyama and K. Yokogawa: Phys. Rev. B, 69 (2004), 174108. https://doi.org/10.1103/PhysRevB.69.174108

25) D. Delafosse: Gaseous Hydrogen Embrittlement of Materials in Energy Technologies, Vol. 1, eds. by R. P. Gangloff and B. P. Somerday, Woodhead Publishing, Cambrigdge, UK, (2012), 247.

26) M. Deutges, H. P. Barth, Y. Chen, C. Borchers and R. Kirchheim: Acta Mater., 82 (2015), 266. https://doi.org/10.1016/j.actamat.2014.09.013

27) R. Kirchheim: Acta Mater., 55 (2007), 5139. https://doi.org/10.1016/j. actamat.2007.05.033

28) Y. Yagodzinskyy, T. Saukkonen, S. Kilpeläinen, F. Tuomisto and H. Hänninen: Scr. Mater., 62 (2010), 155. https://doi.org/10.1016/j. scriptamat.2009.10.005

29) T. Masumura, Y. Seto, T. Tsuchiyama and K. Kimura: Mater. Trans., 61 (2020), 678. https://doi.org/10.2320/matertrans.H-M2020804

30) R. Kirchheim: Scr. Mater., 67 (2012), 767. https://doi.org/10.1016/j. scriptamat.2012.07.022

31) P. J. Ferreira, I. M. Robertson and H. K. Birnbaum: Acta Mater., 46 (1998), 1749. https://doi.org/10.1016/S1359-6454(97)00349-2 